\title{
USE OF AERIAL IMAGES FOR REGULAR UPDATES OF BUILDINGS IN THE FUNDAMENTAL BASE OF GEOGRAPHIC DATA OF THE CZECH REPUBLIC
}

\author{
V. Hron ${ }^{\text {a, } * \text {, L. Halounova }}{ }^{\text {a }}$ \\ ${ }^{a}$ Department of Geomatics, Faculty of Civil Engineering, Czech Technical University in Prague, Thákurova 7, 16629 Prague 6, \\ Czech Republic - (vojtech.hron, lena.halounova)@fsv.cvut.cz
}

Commission IV, WG IV/1

KEY WORDS: Aerial Image, Image Matching, Point Cloud, Digital Surface Model, Spectral Classification

\begin{abstract}
:
Digital aerial images (DAI) include position, elevation and also spectral information (visible bands and near-infrared band) about the captured area. The aim of this paper is to present the possibilities of automatic analysis of DAI for updating of the Fundamental Base of Geographic Data of the Czech Republic with a focus on buildings. Regular updates of buildings (automatic detection of new and demolished buildings) are based on the analysis of coloured point clouds created by an automatic image matching technique from each time period. The created approach compares point clouds from different time periods to each other. The advantage of this solution is that it is independent of the manner of keeping the buildings in the database. It does not matter whether the buildings in the database have correct positions and their footprints correspond to the roof shapes or external walls. The involved method is robust because a digital surface model generated by image matching techniques can contain numerous errors. Shaded areas and objects with blurred textures are problematic for automatic image correlation algorithms and lead to false results. For this reason, derived layers containing additional information are used. Shadow masks (layers with modelled shadows) are used for the verification of indications and to filter out errors in the shaded areas using a contextual evaluation. Furthermore, additional information about the road and railway networks and morphological operations of opening and closing were used to achieve more accurate results. All these information sources are then evaluated using decision logic, which uses the generally applicable rules that are available for different datasets without the need for modification. The method was tested on different datasets with various types of buildings (villages, suburbs and city centres) which cover more than 20 square kilometres. The developed solution leads to very promising results without the need of acquiring new data.
\end{abstract}

\section{INTRODUCTION}

\subsection{Background}

The Czech Office for Surveying, Mapping and Cadastre (further only COSMC) is a state institution that manages the nationwide databases containing topographic information on buildings. These databases are the Cadastre of Real Estate and the Fundamental Base of Geographic Data of the Czech Republic (ZABAGED ${ }^{\circledR}$ in Czech). Both of these databases are currently managed separately because each of them keeps building records in a separate way and for different purposes. ZABAGED $^{\circledR}$ was created by the vectorization of prints of the base map of the Czech Republic at 1:10 000 and thereafter is regularly updated. Updates are mainly performed using photogrammetric methods and eventual field surveys. Aerial images are used as a main source of information for the update process. COSMS acquires every two years (biennial period) digital aerial images (DAI) from the entire territory of the Czech Republic for the purposes of making a seamless orthophoto mosaic. Unfortunately, aerial photographs and from them derived orthophoto maps, are used only in the form of underlying layers during manual updates of ZABAGED ${ }^{\circledR}$.

ZABAGED $^{\circledR}$ contains many errors as a result of many years of continuous operation. Vectorised cartographic material, which was (and still is) used for a map scale of 1:10 000, contains generalized information (e.g. simplified shapes of buildings, shifts of buildings from roads etc.) that cannot be completely compared to aerial images, which express the earth's surface accurately. This form of database does not correspond to today's requirements. COSMC's long-term effort is to satisfy the demands of today's users of spatial data and offer them high quality data (i.e. accurate, consistent and especially current). Currently there is an effort to eliminate these errors and improve the accuracy of ZABAGED ${ }^{\circledR}$ from 1:10 000 to a scale of 1:5000. After that ZABAGED ${ }^{\circledR}$ would be suitable for applications (urban and building planning, planning of technical infrastructure networks etc.) for which its current quality is not convenient. The Land Survey Office (part of COSMC) which is responsible for ZABAGED ${ }^{\circledR}$ begins with an area-wide update of building objects. This updated layer of buildings will be linked to the digital cadastral map and will expand its content. The cadastral map contains in fact only legal relations which may not exactly correspond to reality. The purpose of ZABAGED ${ }^{\circledR}$ is to capture true geographical and physical states. Given this fact, it cannot take information from the cadastre of real estate automatically, but it is necessary to verify the cadastral information by comparing it with the current state which is captured from aerial images.

The problem addressed in this article is how to keep buildings in the database up to date. Manual validation of millions of buildings is not feasible from the perspective of the whole

\footnotetext{
* Corresponding author. This is useful to know for communication with the appropriate person in cases with more than one author.
} 
country. It is necessary to use a sophisticated solution for the future that will solve the task automatically or at least semi-automatically. Detection (preselection) of places, new or demolished building, will simplify and significantly accelerate the work of operators. There are many ways to solve this problem. Analysis of aerial images is not appropriate due to the impossibility to create a true orthophoto. Small overlaps between images, forward overlap $60 \%$ and side forward $25-30 \%$, lead to image shifts of elevated objects (buildings and trees) and this causes too many complications during processing. The principle of finding the differences between buildings in a database and the real state (aerial images) cannot be used, because the database for now contains many buildings that have generalized shapes. However, this method will be applied in the future. The involved solution relates only to the differences between digital surface models, which occurred in a given area. Digital surface models are created based on DAI. DAI have enormous information potential which has not yet been fully exploited in the Czech Republic. Until now, this unique source of information was only partially used in completely separate procedures and by different institutions. This article contains a step-by-step description of the solution including graphic illustrations and output examples.

\subsection{Previous Studies}

Automatic change detection is a topic that has been studied by many research teams around the world. In the available literature many different techniques or strategies can be found. According to one of the previous studies (Bouziani et al., 2010) two strategies exist: image-image comparison and image-map comparison. These strategies can use assisted methods or automatic methods with a pixel-oriented approach or objectoriented approach.

Strategies based on image-image comparison are quite old. Early works from the eighties and nineties (Singh, 1989; Coppin and Bauer, 1996; Lunetta and Elvidge, 1999) used the pixel by pixel approach in order to produce a change image between two different epochs. A very interesting and sophisticated approach was used in (Jung, 2004), which was based on the analysis of low-quality aerial images. This strategy also includes solutions that use laser scanning data instead of image data to detect changes. These solutions are based on a raster-based approach (Murakami et al., 1999; Masaharu and Hasegawa, 2000; Rottensteiner and Briese, 2002; $\mathrm{Vu}$ et al., 2004) or a vector-based approach (Wang and Schenk, 2000; Sampath and Shan, 2007). Some solutions (Matikainen et al., 2004, Rottensteiner et al., 2007) even use aerial images and laser scanning data side by side.

The strategy of image-map comparison uses a recent picture and an existing map to find changes. This strategy can be further split into two sub-strategies: post-extraction method and map-guided method (Bouziani et al., 2010). The first substrategy is based on image primitives that are extracted and thereafter compared to the map's objects (Walter, 1999; Armenakis et al., 2003). This sub-strategy has many disadvantages. The main disadvantage can be that geometry and shape of objects in a map may not correspond to reality (generalization effect). The second sub-strategy uses information from maps to improve the interpretability of images (Bentabet et al., 2003). Methods using geodatabases during the classification process can also be included into this substrategy. Geodatabases have a large information potential. Geometry, meaning of objects and contextual relations between them are important for change detection analysis in very complex environments (Baltsavias, 2004; Holland et al., 2006). Recent studies are based on the combination of different data sources (such as ALS point clouds, aerial images and existing building information) and a prior knowledge (Bouziani et al., 2010; Chen et al., 2012).

In recent years, applications for map (geodatabase) updating were presented. These applications use object-based classification (Walter, 2004), supervised and unsupervised classification (Knudsen and Olsen, 2003) or multiresolution analysis and wavelet transformation (Zhang and Couloigner, 2004). All these works were performed in cooperation with national cartography agencies. The same applies to this article. Unfortunately, the initial state is different in each country. Each country keeps records about buildings in a slightly different way and has various additional data sources. Given this fact, the applicability of the developed processes is often very complicated or even impossible. The following part of the article is dedicated to a description of a developed method for an automatic change detection of buildings, which uses the image-image comparison strategy with pixel and also object-oriented approaches and decision tree logic.

\section{METHODOLOGY}

\subsection{Detection Technology of New and Demolished Buildings}

This chapter describes the detection technology of new and demolished buildings. The processing is based on the use of DAI from each time period and the Digital Terrain Model of the Czech Republic of the 4th generation (DMR 4G in Czech). The following diagram (Figure 1) shows the procedure of processing that can be divided into the following sub-steps:

1. Preparation of colour infrared digital aerial images

2. Generation of point clouds (digital surface model)

3. Normalization of digital surface model

4. Calculation of the differential digital surface model

5. Analysis of models and extraction of additional layers

6. Use of other sources of information

7. Evaluation

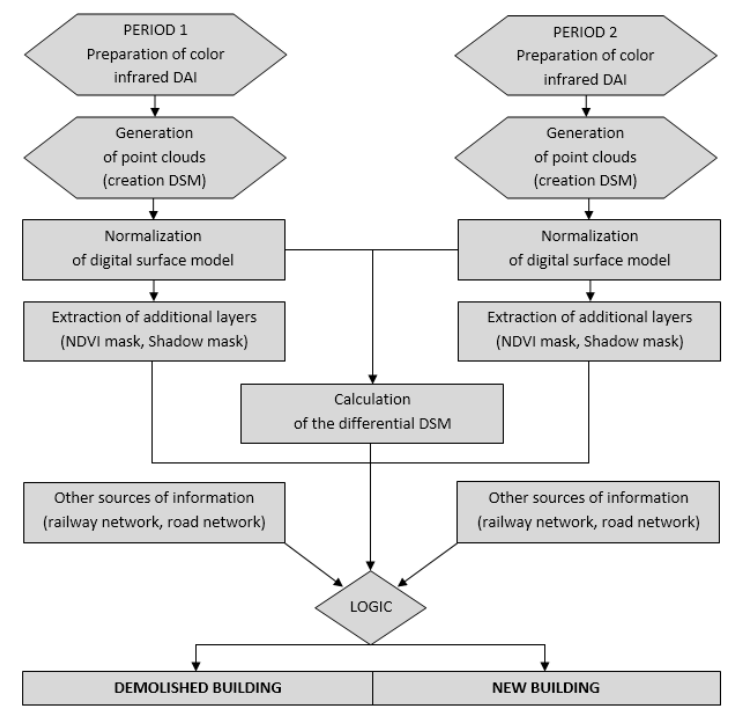

Figure 1. Process diagram 
2.1.1 Preparation of Colour Infrared Digital Aerial Images: Preparation of colour infrared (CIR) digital aerial images consists of using an infrared channel. Since 2010, the Land Survey Office performs the collection of aerial photographs (GSD approximately $20 \mathrm{~cm}$ ) with a digital aerial camera. A digital aerial camera captures images in the visible and near-infrared spectrum. The near-infrared (NIR) channel is a very good source of information about the state of vegetation and it is also suitable for the separation of vegetation areas of an image from other objects. This colour channel is much more important than the blue channel, and therefore aerial images were prepared in false colours, created with the combination of near-infrared, red and green channels instead of the traditional combination of red, green and blue channels. The following Figure 2 shows the aerial images in false colours.
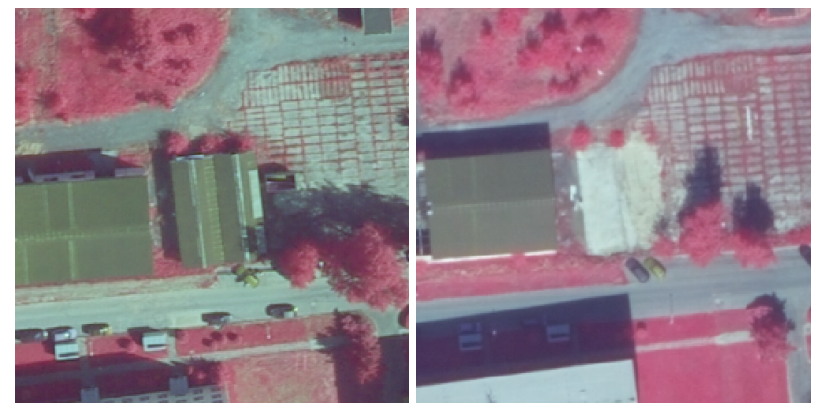

Figure 2. Left: CIR image (2010) Right: CIR image (2012)

2.1.2 Generation of Point Clouds: Aerial photographs in false colour combination are subsequently used for generating point clouds. The point clouds were derived with the image matching (IM) technique in MATCH-T DSM (further only MATCH-T) software. MATCH-T comes from INPHO $\mathrm{GmbH}$ (now Trimble) that focuses on the development of software products for photogrammetry, processing of geoinformation and digital modelling. MATCH-T uses aerial images with known elements of interior and exterior orientation thus after calculating the automatic aerotriangulation. The processing of images was carried out with stereo-pairs. This approach has proven to be the most appropriate, because the custom merging technique of point clouds (Figure 3 ) leads to better results in comparison with standard software output (Figure 4).

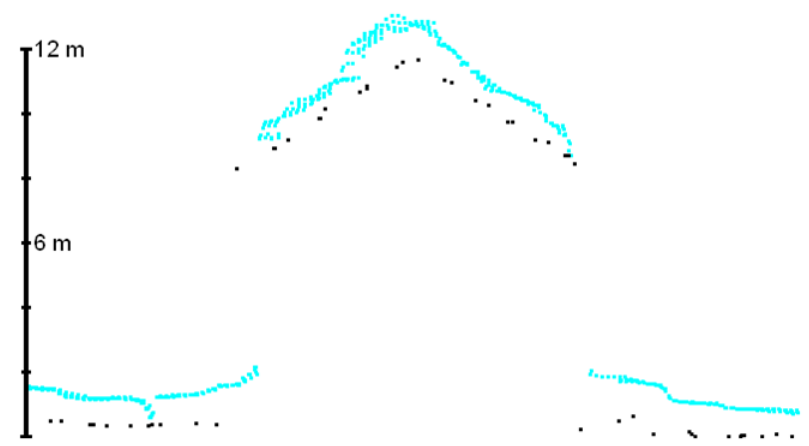

Figure 3. Profile of the reference ALS point (black) cloud and IM point cloud with offset $+1 \mathrm{~m}$ (cyan, custom merging technique)

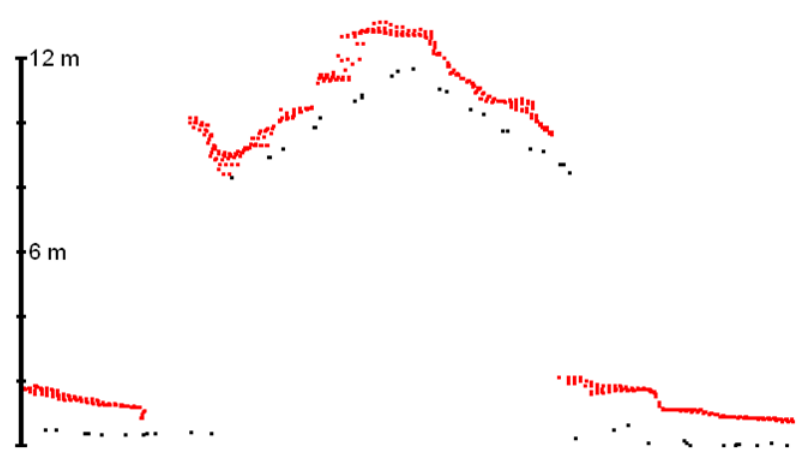

Figure 4. Profile of the reference ALS point cloud (black) and IM point cloud with offset +1 m (red, MATCH-T output)

The results of processing the stereo-pairs are point clouds representing a digital surface model (DSM). Point clouds are automatically coloured (software version 5.4 and higher) during generation process. Colourization is based on the input false colour images. This ensures spatial consistency between the spectral and elevation information, which is important for proper evaluation. The output density of the point cloud is reduced to 4 points per square meter. Information reduction is necessary because the aerial photographs have a GSD approximately $20 \mathrm{~cm}$, so it is possible to achieve a density of up to 25 points per square meter. It would be very time consuming to process such an amount of data. IM point cloud was compared to reference airborne laser scanning (ALS) data with the following results (see Figure 5). The figure shows that the height differences of stable surfaces (houses, roads, etc.) between the ALS data and IM point cloud are in the range $-0,5$ to $0,5 \mathrm{~m}$ (green value).

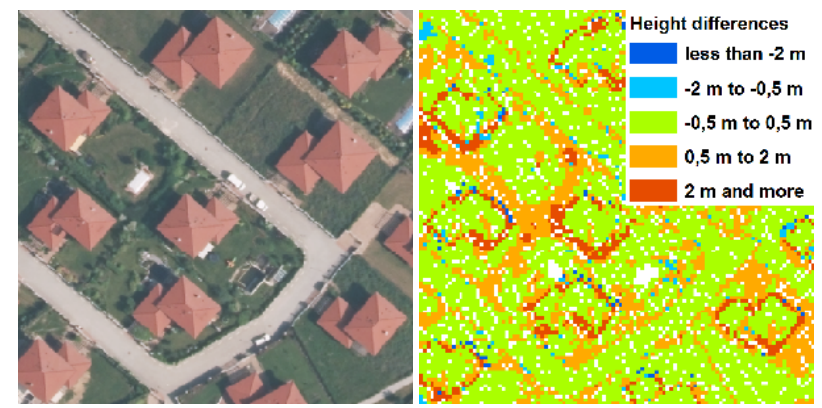

Figure 5. Comparison of ALS and IM point clouds (raster form)

2.1.3 Normalization of Digital Surface Model: Normalization of point clouds is a process in which the height of points is reduced by the height of the digital terrain model (DTM). The height of each point is equal to the relative height above the ground in a normalized point cloud. Figure 6 shows two normalized point clouds transferred into a raster form (normalized DSM, shortly nDSM), where the grayscale does not represent absolute height values (altitude) but relative heights above the ground. This type of visualization eliminates height disparity of the terrain and gives a better idea about objects on the earth's surface (buildings, vegetation, etc.). 

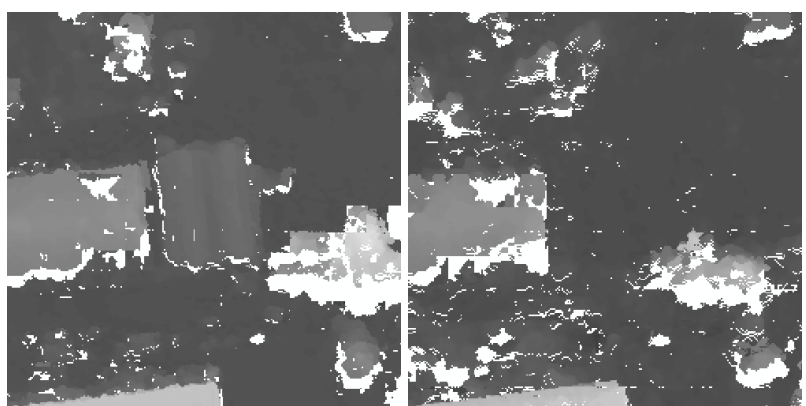

Figure 6. Left: normalized DSM (2010)

Right: normalized DSM (2012)

The Digital Terrain Model of the Czech Republic of the 4th generation (DMR 4G) was used for the normalization of point clouds. DMR 4G covers the entire territory of the Czech Republic. It was created from the ALS data that were acquired for the purpose of new altimetry mapping of the Czech Republic. DMR 4G is provided in a digital form as heights of discrete points in a regular grid $(5 \times 5 \mathrm{~m})$ with total standard error of height $0.3 \mathrm{~m}$ in the bare terrain and $1 \mathrm{~m}$ in forested terrain. Figure 7 shows the classified nDSMs in raster form where objects located more than two meters above the ground are shown in purple and objects with lower height are gray.

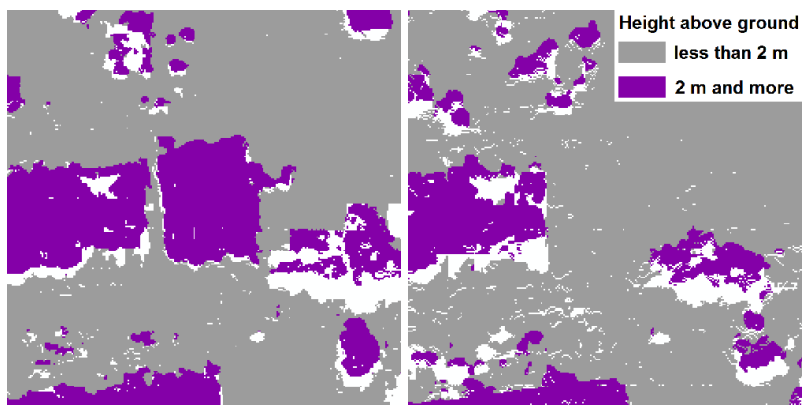

Figure 7. Left: classified nDSM (2010)

Right: classified nDSM (2012)

2.1.4 Calculation of the Differential Digital Surface Model: Calculation of the differential digital surface model (DDSM) is a process where nDSMs from two different periods are subtracted from each other. In this paper, two different periods correspond to the biennial period of acquisition of DAI. Figure 8 [left] represents classified DDSM. Height differences were categorized into two classes (see legend of Figure 8). The threshold value is 2 meters height above the ground. Height differences within the range $-2 \mathrm{~m}$ and $+2 \mathrm{~m}$ are not shown. The threshold value was determined with respect to the minimum height of the buildings (one-level building has a minimum height of 2.5 meters) and was tightened in order to eliminate height inaccuracies $( \pm 0.5 \mathrm{~m})$ of the DSM created with the IM technique. Figure 8 [right] shows a simplified and classified DDSM. Simplification consists of filtering out small objects (area less than $20 \mathrm{~m}^{2}$ ) and smoothing the boundaries of objects, which was done through morphological operations of closing and opening using a circular mask.

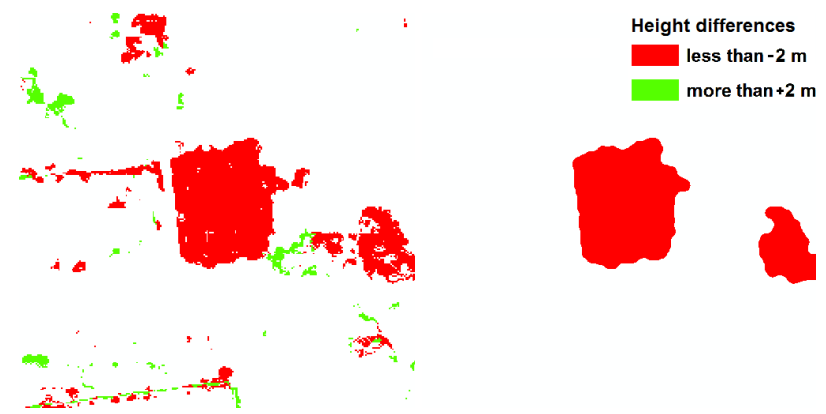

Figure 8. Left: classified DDSM

Right: classified DDSM after filtering and smoothing

2.1.5 Analysis of Models and Extraction of Additional Layers: CIR digital aerial images allow for easy visual identification of vegetation from other objects. CIR images are also suitable for forming a mask based on a calculation of normalized differential vegetation index (NDVI). The classified NDVI mask is shown in Figure 9. All parts of the image that capture healthy vegetation are represented in green, while yellow expresses all other (mostly man-made) objects. This mask was used to filter out indications that belong only to vegetation and not to building indications caused by construction or the demolition of buildings.

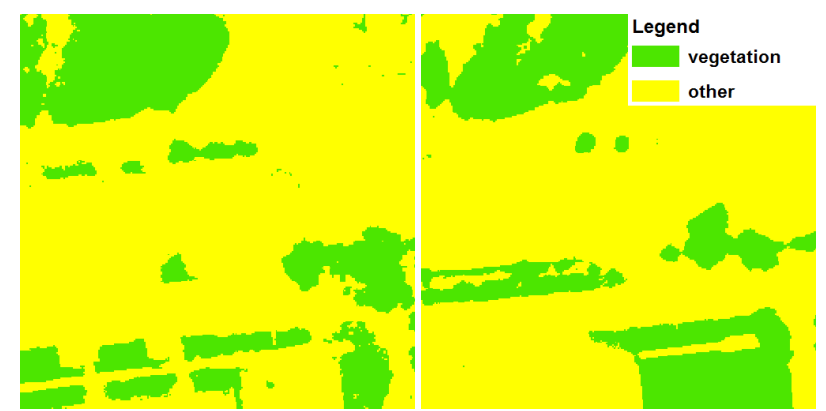

Figure 9. Left: classified NDVI mask (2010)

Right: classified NDVI mask (2012)

Identification of shadows was used for the exact identification of scene parts, which were shadowed at the time of acquisition of the DAI. This technique is based on the spectral evaluation of the image information and the calculation of the hill shade mask based on DSM. For the calculation of a hill shade mask, it is necessary to know the information about the time of the image acquisition. Based on this information, the exact position of the sun in the sky (elevation and azimuth) is calculated. The shadow mask is obtained on the basis of a combination of both data sources. The combination of both data sources leads to a very precise and robust identification of shadows (Figure 10) which were subsequently used for the evaluation of indications. Improper indications related to new or demolished buildings can be excluded (however, not quite always) using contextual evaluation of shadows. A new building should cast a shadow of an appropriate length, a demolished building should not. It is necessary to take into account the shape of the DSM in the vicinity during this evaluation. This evaluation is not always conclusive for height complex areas (for example densely urbanized areas). 


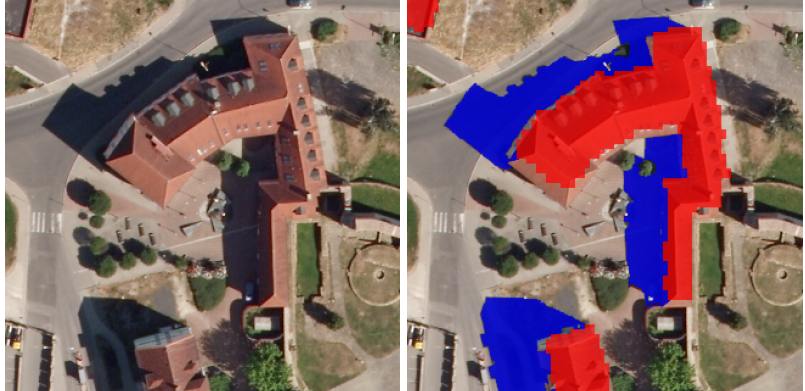

Figure 10. Left: aerial image

Right: classified buildings (red) and their shadows (blue)

A created mask of shadows also enables the elimination of indications caused by an incorrect DSM due to the lack of textures in the source images. This is typical for the underexposed parts of a scene (shadowed areas) and for the overexposed parts of a scene (facing towards the sun). Overvaluations of a DSM (buildings are larger by drop shadows) are typical for the shadowed areas. Under valuations of a DSM (buildings are smaller by the overexposed parts) characterize the overexposed areas. An example of the overexposed parts of a scene is shown in Figure 11 and Figure 12
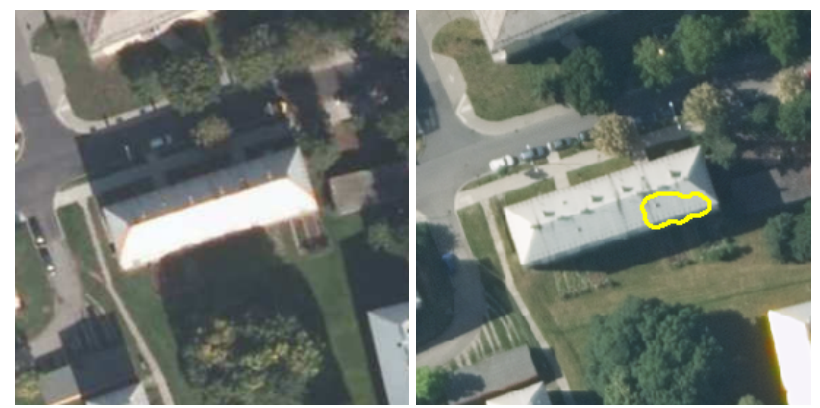

Figure 11. Left: aerial image (2010) Right: aerial image (2012) with a false indication of a new building
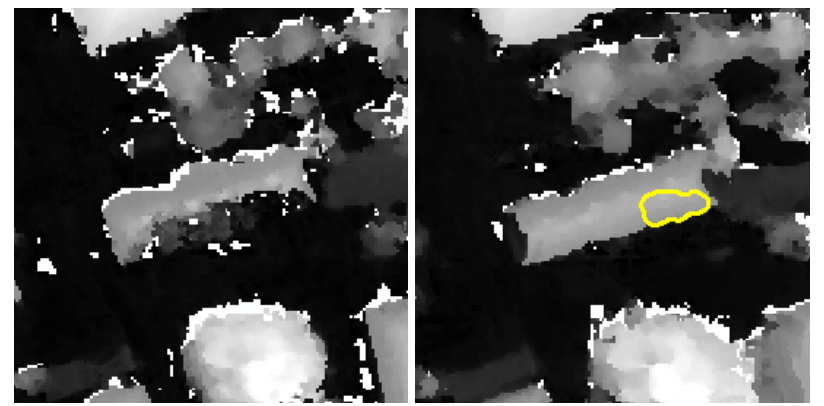

Figure 12. Left: normalized DSM (2010) Right: normalized

DSM (2012) with a false indication of a new building

\subsubsection{Use of Other (Additional) Sources of Information:}

The use of other sources of information achieves more accurate results. The ZABAGED ${ }^{\circledR}$ database was used directly as an additional source of information. This database includes 123 basic types of geographic objects. Information about road networks, railway networks, car parks and handling areas were used from this database. Many erroneous indications may be caused by large vehicles like trucks and buses (Figure 13) or trains. Storage and handling areas generate a certain number of problems as well. Containers, goods stacked on pallets, tree trunks on open storage areas change their position in time (Figure 14). These indications are difficult to characterize because they are too varied (shape/height/colour etc.). That is the reason why it is suitable to exclude these areas from the processing while using additional sources of information.

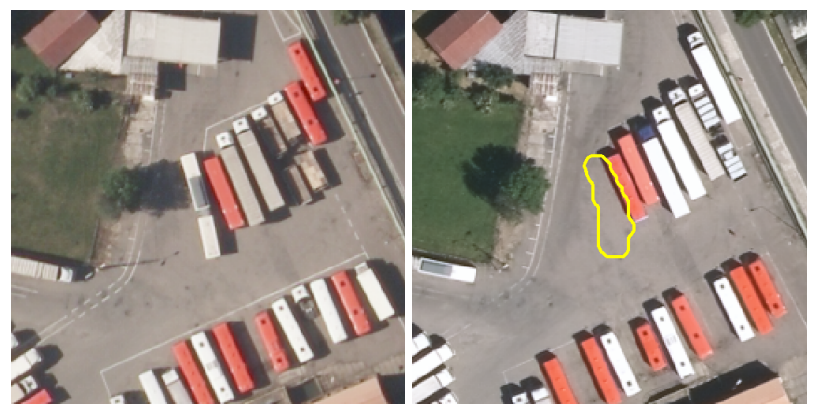

Figure 13. Left: aerial image (2010) Right: aerial image (2012) with a false indication of a demolished building
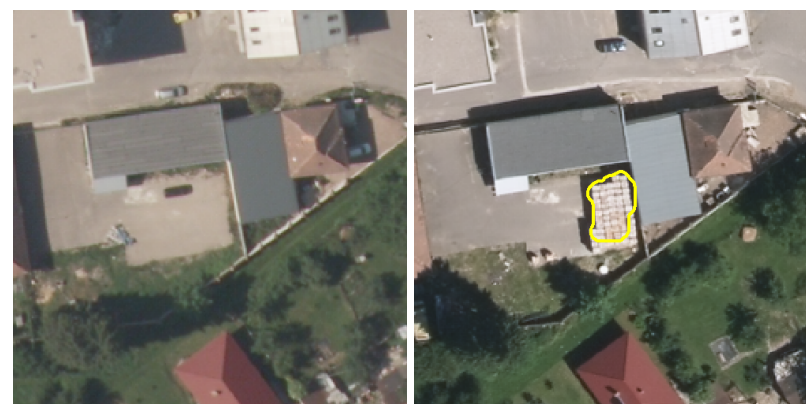

Figure 14. Left: aerial image (2010) Right: aerial image (2012) with a false indication of a new building

2.1.7 Evaluation: The outputs from the previous sub-steps (point clouds - subchapter 2.1.2, normalized DSM - subchapter 2.1.3, differential DSM - subchapter 2.1.4, additional layers subchapter 2.1.5 and other sources of information - subchapter 2.1.6) enter into evaluation, which is based on decision logic. The evaluation is carried out in two steps. The first step consists in finding all indications that meet the criteria specified in the following decision table (Table 15). This simple evaluation is based only on nDSMs, height difference and NDVI masks. This step results in a large number of indications.

\begin{tabular}{|l|c|c|}
\hline & PERIOD 1 & PERIOD 2 \\
\hline HEIGHT DIFFERENCE: LESS THAN -2 m \\
\hline new building & trees & building \\
\hline demolished building & building & impervious \\
\hline demolished building & building & grass \\
\hline HEIGHT DIFFERENCE: MORE THAN +2 m \\
\hline new building & grass or trees & building \\
\hline new building & impervious & building \\
\hline CONSTANT HEIGHT \\
\hline new building & trees & building \\
\hline \multicolumn{3}{|c|}{ comment: positive NDVI, negative NDVI } \\
\hline
\end{tabular}

Table 15. Simplified decision table

All indications are analyzed and filtered on the basis of additional sources of information in the second step. Located indications are analysed based on the object-oriented approach. This approach uses the contextual evaluation of shadows (subchapter 2.1.5), a spectral evaluation using GLCM (Gray- 
Level Co-occurrence Matrices) texture features, HSI (HueSaturation-Intensity) colour model and additional data sources (subchapter 2.1.6). The result of the evaluation is to decide whether the indication is correct (new or demolished building) or if it is not correct. The following figure (Figure 16) shows the final form of the detection of new buildings and Figure 17 captures the final form of the detection of demolished buildings. The changes were successfully detected in both cases. Both figures also show that the shapes of the buildings were determined very precisely and correspond to the real state.
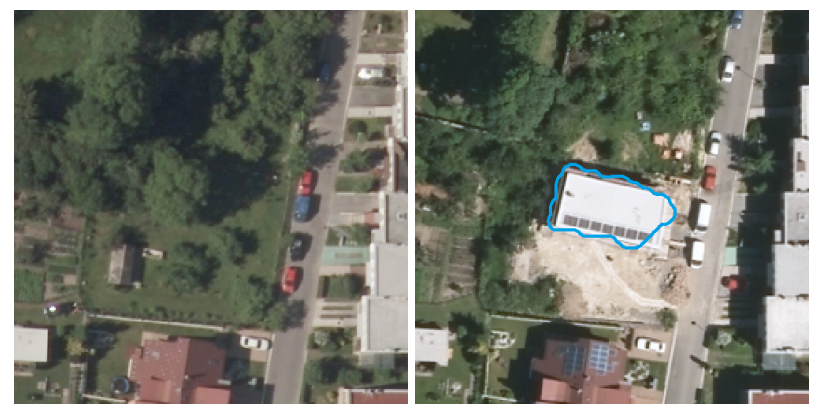

Figure 16. Left: aerial image (2010) Right: aerial image (2012) with an indication of a new building
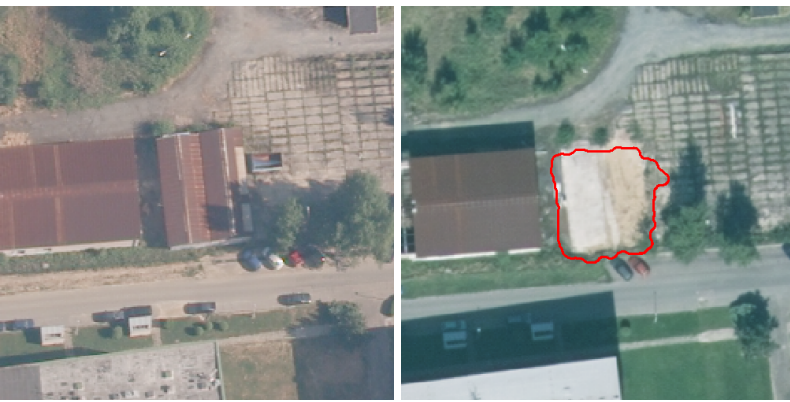

Figure 17. Left: aerial image (2010) Right: aerial image (2012) with an indication of a demolished building

This developed technology was tested on a large area with the following results of detection (see Table 18) of new and demolished buildings. It was determined that almost all new (133/139) and demolished (68/70) buildings were detected in the test areas. This result can be considered excellent. The ratio of true and false indications is also very good. For villages and suburbs are typical completely new and demolished buildings. For small cities and city centers are typical smaller reconstructions. However, a small reconstruction is difficult to identify. The biggest problem was the detection of demolished buildings in the city centre. Many errors were caused by felled trees that were evaluated in the first period as buildings because they had a negative NDVI index.

\begin{tabular}{|c|c|c|c|c|c|}
\hline \multirow{3}{*}{$\begin{array}{c}\text { AREA } \\
\text { (evaluated area) }\end{array}$} & \multicolumn{5}{|c|}{ NEW BUILDINGS } \\
\hline & \multirow{2}{*}{$\begin{array}{c}\text { real } \\
\text { changes }\end{array}$} & \multicolumn{4}{|c|}{ number of indications } \\
\hline & & SUM & false & true & ratio \\
\hline $\begin{array}{c}\text { village } \\
\left(15 \mathrm{~km}^{2}\right)\end{array}$ & 82 & 83 & 3 & 80 & $96 \%$ \\
\hline $\begin{array}{l}\text { small city } \\
\left(5 \mathrm{~km}^{2}\right)\end{array}$ & 16 & 18 & 4 & 14 & $78 \%$ \\
\hline $\begin{array}{l}\text { suburb } \\
\left(5 \mathrm{~km}^{2}\right)\end{array}$ & 22 & 23 & 2 & 21 & $91 \%$ \\
\hline $\begin{array}{l}\text { city centre } \\
\left(5 \mathrm{~km}^{2}\right)\end{array}$ & 19 & 22 & 4 & 18 & $82 \%$ \\
\hline
\end{tabular}

\begin{tabular}{|c|c|c|c|c|c|}
\hline \multirow{2}{*}{$\begin{array}{c}\text { AREA } \\
(\text { evaluated area })\end{array}$} & \multicolumn{5}{|c|}{ DEMOLISHED BUILDINGS } \\
\cline { 2 - 6 } & changes & \multicolumn{4}{|c|}{ number of indications } \\
\cline { 3 - 6 } & 23 & 25 & 4 & 21 & $84 \%$ \\
\hline $\begin{array}{c}\text { village } \\
\left(15 \mathrm{~km}^{2}\right)\end{array}$ & 10 & 15 & 5 & 10 & $67 \%$ \\
\hline $\begin{array}{c}\text { small city } \\
\left(5 \mathrm{~km}^{2}\right)\end{array}$ & 28 & 36 & 8 & 28 & $78 \%$ \\
\hline $\begin{array}{c}\text { suburb } \\
\left(5 \mathrm{~km}^{2}\right)\end{array}$ & 9 & 23 & 14 & 9 & $39 \%$ \\
\hline $\begin{array}{c}\text { city centre } \\
\left(5 \mathrm{~km}^{2}\right)\end{array}$ & &
\end{tabular}

Table 18. Results of detection

\section{CONCLUSION}

Every year aerial photographs from one half of the territory of the Czech Republic are collected. Aerial photographs are used as one of the main information sources for regular updates of national map products. One of these products is also ZABAGED $^{\circledR}$. Until now, aerial photographs were used only for the manual editing of data during stereoscopic observation, alternatively, in the form of an orthophoto of the Czech Republic used as an underlayer in GIS. The current requirements on the quality of spatial data (positional accuracy and topicality) cannot be resolved by classical methods, which are mainly based on manual work. The aim of this paper was to show the potential of aerial photographs for the Land Survey Office and introduce new procedures of processing this data type. The above-described technology of automatic detection of new and demolished buildings represents only one of the possible areas of application. Currently a possibility of using the image correlation technique as an alternative to ALS for updating the national elevation databases is being considered. Spectral, textural and contextual interpretation of aerial photographs represent underrated techniques that are still waiting for their wider application by government institutions. To exploit the full potential of aerial photographs, a collaboration of experts in photogrammetry, remote sensing and computer vision is suitable.

\section{REFERENCES}

Armenakis, C., Leduc, F., Cyr, I., Savopol, I., Cavayas, F., 2003. A comparative analysis of scanned maps and imagery for mapping applications. ISPRS Journal of Photogrammetry and Remote Sensing, 57 (5-6), pp. 304-314.

Baltsavias, E.P., 2004. Object extraction and revision by image analysis using existing geodata and knowledge: Current status and steps towards operational systems. ISPRS Journal of Photogrammetry and Remote Sensing, 58 (3-4), pp. 129-151.

Bentabet, L., Jodouin, S., Ziou, D., Vaillancourt, J., 2003. Road vectors update using SAR imagery: A snake based method. IEEE Transactions on Geosciences and Remote Sensing, 41 (8), pp. 1785-1803.

Bouziani, M. Goïta, K., Heb, D.C., 2010. Automatic change detection of buildings in urban environment from very high spatial resolution images using existing geodatabase and prior knowledge. ISPRS Journal of Photogrammetry and Remote Sensing, 65, pp. 143-153. 
Coppin, P.R., Bauer, M.E., 1996. Digital change detection in forest ecosystems with remote sensing imagery. Remote Sensing Reviews, 13 (3-4), pp. 207-234.

Holland, D.A., Boyd, D.S., Marshall, P., 2006. Updating topographic mapping in Great Britain using imagery from highresolution satellite sensors. ISPRS Journal of Photogrammetry and Remote Sensing, 60 (3), pp. 212-223.

Chen, L.C., Huang, C.Y., and Teo, T.A., 2012. Multi-type change detection of building models by integrating spatial and spectral information. International Journal of Remote Sensing, $33(6)$, pp. $1655-1681$

Jung, F., 2004. Detecting building changes from multitemporal aerial stereopairs. ISPRS Journal of Photogrammetry and Remote Sensing, 58, pp. 187-201.

Knudsen, T., Olsen, B.P., 2003. Automated change detection for updates of digital map databases. Photogrammetric Engineering \& Remote Sensing, 69 (11), pp. 1289-1296.

Lunetta, R.S., Elvidge, C.D., 1999. Remote sensing change detection. In: Environmental Monitoring Methods and Applications. Taylor \& Francis, London, pp. 318.

Masaharu, H. and Hasegawa, H., 2000. Three-dimensional city modeling from laser scanner data by extracting building polygons using region segmentation method. International Archives of Photogrammetry and Remote Sensing, 33, pp. 556562.

Matikainen, L., Hyyppä, J., Hyyppä, H., 2004. Automatic detection of changes from laser scanner and aerial image data for updating building maps. International Archives of the Photogrammetry, Remote Sensing and Spatial Information Sciences, 35, pp. 434-439.

Murakami, H., Nakagawa, K., Hasegawa, H., Shibata, T. and Iwanami, E., 1999. Change detection of buildings using an airborne laser scanner. ISPRS Journal of Photogrammetry and Remote Sensing, 54, pp. 148-152.

Rottensteiner, F. and Briese, C., 2002. A new method for building extraction in urban areas from high-resolution LIDAR data. International Archives of Photogrammetry and Remote Sensing, 34, pp. 295-301.

Rottensteiner, F., Trinder, J., Clode, S. and Kubik, K., 2007. Building detection by fusion of airborne laser scanner data and multi-spectral images: performance evaluation and sensitivity analysis. ISPRS Journal of Photogrammetry and Remote Sensing, 62, pp. 135-149.

Sampath, A. and Shan, J., 2007. Building boundary tracing and regularization from airborne LIDAR point clouds. Photogrammetric Engineering and Remote Sensing, 73, pp. 805-812.

Singh, A., 1989. Digital change detection techniques using remotely-sensed data. International Journal of Remote Sensing, 10 (6), pp. 989-1003.

Vu, T.T., Matsuoka, M. and Yamazaki, F., 2004. LIDAR-based change detection of buildings in dense urban areas. IEEE International Geoscience and Remote Sensing Symposium, 5, pp. 3413-3416.
Walter, V., 1999. Comparison of the potential of different sensors for an automatic approach for change detection in GIS databases. In: Integrated Spatial Databases: Digital Images and GIS. International Workshop ISD '99. In: Lecture Notes in Computer Science, Springer, pp. 47-63.

Walter, V., 2004. Object-based classification of remote sensing data for change detection. ISPRS Journal of Photogrammetry and Remote Sensing, 58 (3-4), pp. 225-238.

Wang, Z. and Schenk, T., 2000. Building extraction and reconstruction from lidar data. International Archives of Photogrammetry and Remote Sensing, 33, Amsterdam, The Netherlands, unpaginated CD-ROM.

Zhang, Q., Couloigner, I., 2004. A framework for road change detection and map updating. International archives of the photogrammetry. Remote Sensing and Spatial Information Sciences, 35 (B2), pp. 729-734. 